\title{
Multi-scale regional forest carbon density estimation based on regression and sequential Gaussian co-simulation
}

\author{
Gaoyun SHEN $^{1} \quad$ Maozhen ZHANG ${ }^{1,2}$ \\ ( ${ }^{1}$ Couege of Environmental \& Resource Sciences, Zhenjiang A\&F University of Lin'an Zhejiang 311300 , \\ China; ${ }^{2}$ Zhejiang Provincial Key Laboratory of Carbon Cycling in Ecosystems and Carbon Sequestration)
}

\begin{abstract}
By applying nonlinear regression of a unary cubic equation and sequential Gaussian co-simulation to forest inventory (plot) data in Xianju County, Zhejiang, from 2008, and Landsat TM image data collected in the same region in 2007, this research estimated the above-ground forest carbon density and its distributions at $30 \mathrm{~m} \times$ $30 \mathrm{~m}$ and $270 \mathrm{~m} \times 270 \mathrm{~m}$ resolutions, and analyzed the results comparatively. The results showed that the above-ground forest carbon density of Xianju County was continuously distributed, and was surrounded by high carbon density forestland, and the majority of the intermediate region was filled with low carbon density non-forestland. Using the random sampling method, the total carbon estimation is 5,289,437.11 Mg. At $30 \mathrm{~m} \times 30$ $\mathrm{m}$ resolution, with nonlinear regression of a unary cubic equation, the sum of carbon is $5,246,749.81 \mathrm{Mg}$, and the $\mathrm{R}^{2}$ of the model is 0.1353 . At the same scale, with sequential Gaussian co-simulation, the sum of carbon is $5,692,875.69 \mathrm{Mg}$, and the $\mathrm{R}^{2}$ of the model is 0.6203 . Compared with the results in the $270 \mathrm{~m} \times 270 \mathrm{~m}$ resolution, the former total carbon amount is larger, the range of distribution is wider, and the model's precision is higher. Analyzing the two methods, the results estimated by the sequential Gaussian co-simulation are better than those of the unary cubic equation nonlinear regression of regional forest carbon density estimates. The result of sequential Gaussian co-simulation, which considers the spatial distribution of carbon density, is closer to that calculated from plot data, and better represents the continuous change of carbon distribution.
\end{abstract}

Key words: forest carbon storage; carbon density; carbon distribution; sequential Gaussian co-simulation; multi-scale

Forest ecosystem is the main constitute part of the terrestrial ecosystem, which includes lots of terrestrial ecosystem organic carbon stock. As the important component part of global climate system, forests play a very essential role on terrestrial ecosystem carbon cycle, and therefore, take effect in the balance of the regulation of the global carbon and in slowing the rise of the greenhouse gas concentrations in the atmosphere ${ }^{[1]}$. The regional forest carbon distribution which is key to the study of forest ecosystem and relevant decisions has been attracted into forest ecology and other related fields recently ${ }^{[2]}$. Although there are lots of studies on vegetation carbon stock and density of forest ecosystem ${ }^{[3-5]}$, most studies focused on the overall forest carbon stock estimation $^{[4-7]}$, the studies about forest carbon distribution are not enough ${ }^{[8]}$. Gaining regional forest carbon stock and its distribution timely and accurately is of great significance to evaluate the ability of forest $\mathrm{CO}_{2}$ source sink ${ }^{[9]}$.

Forest carbon distribution estimation is a spatial estimation problem. Traditional statistical methods provide the estimation of overall eigenvalues, and the results of random sampling are only the estimation of total, variance and the sampling precision calculated by variance, which are

Funding support: National Science Foundation of China (30972360).

* Corresponding author: Maozhen ZHANG, zhangmaozhen@163.com

(C) 2016. This manuscript version is made available under the Elsevier user license 
unable to obtain the spatial carbon distribution. But the high accuracy data of the regional forest carbon distribution is significant to forest resource management, regional carbon source evaluation and carbon trading. Geostatistics based on spatial autocorrelation theory provide a method to discuss spatial distribution about these characteristics so that can solve the basic problems of the spatial estimation theoretically ${ }^{[10]}$. In recent years, many comparative studies between Kriging interpolation (Kriging) and sequential Gaussian simulation (sequential Gaussian co-simulation, SGCS) are conducted in the soil science and ecology fields ${ }^{[11-14]}$. Analyzing the results, the estimated value of forest carbon is a regionalized variable, but the Kriging has its strong smooth effect as well as the method of ordinary Kriging which is a kind of Kriging interpolation methods. However, the spatial stochastic simulation method of geostatistics can overcome the defects of Kriging method ${ }^{[15]}$. It views the data as a whole to restore the overall spatial structure so that it can better pursuit the reality of simulation and spatial distribution. At the same time, stochastic simulation can be directly used in the study of spatial uncertainty which is also a lack of Kriging method.

In addition to the use of geostatistics theory, the regional forest carbon storage can also be estimated by regression method. Taking good advantage of regional remote sensing data and plot data to build regression model can also estimate the regional distribution of forest carbon stock. But, at present in terms of the spatial distribution of forest carbon, there are not enough comparative studies between regression and sequential Gaussian co-simulation methods at different resolutions. Based on Forest Inventory (plot) data in Xianju county, this research estimated the above-ground forest carbon density and its distribution at $30 \mathrm{~m} \times 30 \mathrm{~m}$ and $270 \mathrm{~m} \times 270 \mathrm{~m}$ resolutions with nonlinear regression of a unary cubic equation and sequential Gaussian co-simulation respectively. After simulation, the results were used to compare with the plot data to analyze the spatial differences, and then evaluate these two methods.

\section{Study area}

Xianju county $\left(120^{\circ} 17^{\prime} 16^{\prime \prime}-120^{\circ} 55^{\prime} 51^{\prime \prime E}, 28^{\circ} 28^{\prime} 14^{\prime \prime}-28^{\circ} 48^{\prime} 59^{\prime \prime} \mathrm{N}\right)$ is located in the southeast of Zhejiang province, east-west length $63.6 \mathrm{~km}$, north-south width $57.3 \mathrm{~km}$. The total area is $2013.18 \mathrm{~km}^{2}$ which is made up of $80.6 \%$ of hilly mountainous area and $11.1 \%$ of plain. The county is typical subtropical monsoon climate, warm and humid, four distinctive seasons, and the average annual precipitation is $1444 \mathrm{~mm}$ and the sunshine hours are $1786 \mathrm{~h}$.

The forestry land area is $1.64583 \times 10^{5} \mathrm{hm}^{2}$ including $1.53369 \times 10^{5} \mathrm{hm}^{2}$ of forestland, $6.289 \times 10^{5} \mathrm{hm}^{2}$ of scrubland, $2.579 \times 10^{3} \mathrm{hm}^{2}$ of young afforested land and $1.889 \times 10^{3} \mathrm{hm}^{2}$ of non-forest area. The forest coverage rate is $77.9 \%$ and the total forest volume amounts to $5.555 \times 10^{6} \mathrm{~m}^{3}(2008)$. 


\section{Data sources and research methods}

\subsection{Data sources}

\subsubsection{The Landsat TM remote sensing image data}

The image data is a Landsat TM image of 2007(October) in the study area. Because the sixth band of Landsat TM sensor is an infrared band which mainly receives heat radiation information that will not be used for the forest carbon density estimation. This study adopts six bands, from first band to fifth band and seventh band, the spatial resolution is $30 \mathrm{~m} \times 30 \mathrm{~m}$. Firstly, the image should be processed with geometric correction and radiation correction. On the basis of better quality image, we should extract these six bands' pixel values from corresponding location plots for calculating band ratio in different combinations. After correlation analysis in the SPSS20.0, the highest correlation coefficient band ratio calculated from [forth band/(fifth band + seventh band)] was selected to participate in the regression estimation and sequential Gaussian co-simulation.

\subsubsection{The above-ground sampling survey data}

The study adopts Forest Inventory (plot) data in Xianju county, Zhejiang in 2008.With the scope of the whole county, the survey set square plots in the spacing of $2 \mathrm{~km} \times 3 \mathrm{~km}$ with the mechanical sampling method. Each plot area is $0.08 \mathrm{hm}^{2}(28.28 \mathrm{~m} \times 28.28 \mathrm{~m})$ and the number of plots is 302 , of which forestland is 251 , accounting for $83.11 \%$. The carbon density calculating from plot data was used to build simulated model.

\subsection{Data preprocessing}

\subsubsection{Resampling}

Based on the min resolution of MODIS image $(250 \mathrm{~m} \times 250 \mathrm{~m})$, the image from Landsat TM was resized from $30 \mathrm{~m} \times 30 \mathrm{~m}$ to $270 \mathrm{~m} \times 270 \mathrm{~m}$. Both images are used respectively to estimate carbon density in multi-scale, so that we can analyze the estimated results of forest carbon density in different resolutions.

\subsubsection{Estimation of plot forest carbon stock}

According to the 302 above-ground effective plots per wood examining records and existing documents, the single plant's above-ground biomass was calculated with the recorded model and then added up biomass of single plant to the total forest biomass. Referencing the average carbon/biomass conversion coefficient 0.5 , the forest total biomass was converted to carbon stock. Finally, the above-ground forest carbon stock would be converted into carbon density according to the plots area ${ }^{[19]}$.

\subsubsection{Test normal distribution of data}

Through the frequency distribution histogram of the forest carbon density in study area, we 
can know whether the data distribution was normal, which is the premise to use sequential Gaussian co-simulation to estimate the spatial distribution of forest carbon density. Only the data approximately obeys the normal distribution, can the simulation results be more effective. Using the histogram drawing function of SPSS20.0 for testing the normal distribution of forest carbon density in study area, we found that the training plots data didn't meet the normal distribution. However, after the cube root calculation, the rest of the plots carbon density except the 0 value tended to be normal distribution that roughly satisfied the requirement of sequential Gaussian co-simulation ${ }^{[20]}$. Therefore, we should use the cube root transformed data in the calculation of variation function

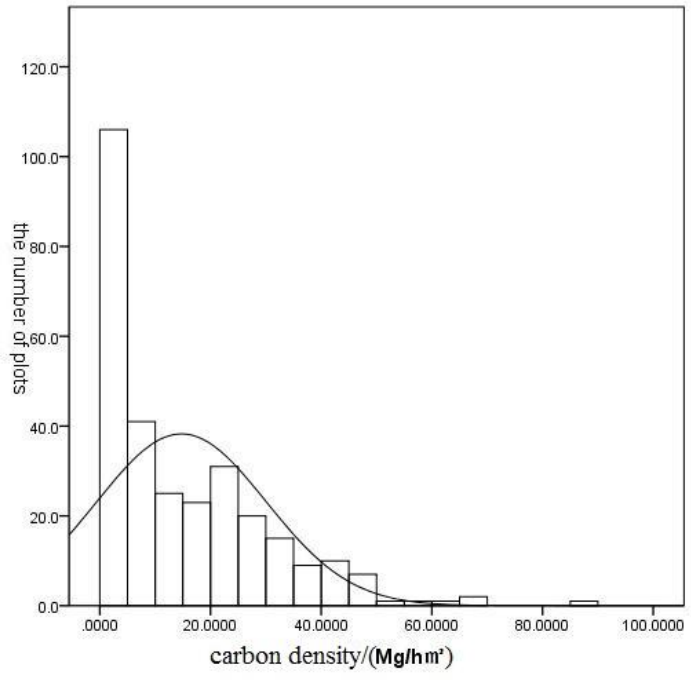

Figure 1 Forest carbon density above ground in $\operatorname{plot}\left(\mathrm{Mg} / \mathrm{hm}^{2}\right)$

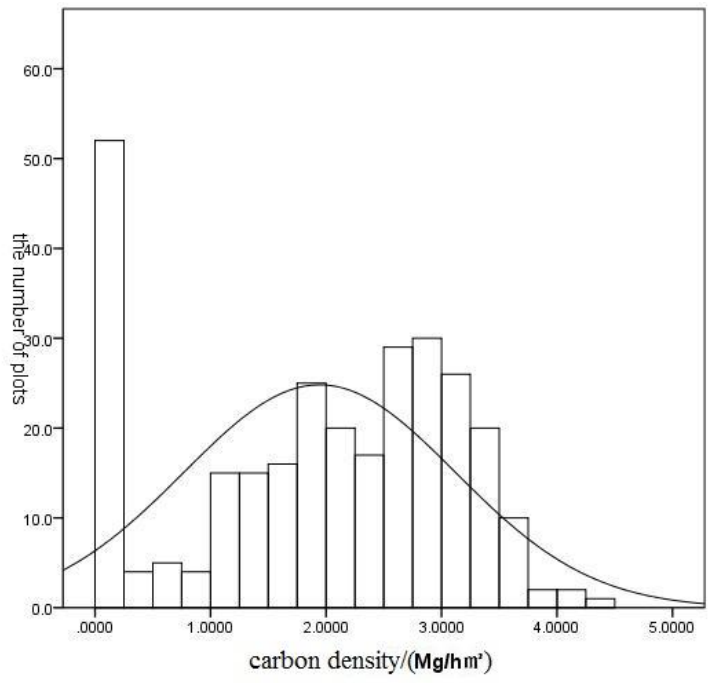

Figure 2 Carbon density by cube root conversion

\subsection{Method of forest carbon distribution estimation}

\subsubsection{Nonlinear regression of a unary cubic equation}

The nonlinear regression is a method to estimate the relationship between dependent variable and independent variable because of the assumption that there is a nonlinear regularity between these two variables. Generally speaking, the nonlinear regression method can reflect the relationship among objective phenomenon more correctly than the linear regression method. Nonlinear regression of a unary cubic equation has the characteristic of nonlinearity and the advantage of the low complexity.

The relationship between forest carbon density and band ratio of TM4/ (TM5+TM7) was cubic. Building the model: $y=a x^{3}+b x^{2}+c x+d$, in this model, $y$ is carbon density, $x$ is the value of band ratio of TM4/ (TM5+TM7), $a, b, c$ and $d$ are solve-for parameters.

The images of $30 \mathrm{~m} \times 30 \mathrm{~m}$ and $270 \mathrm{~m} \times 270 \mathrm{~m}$ resolutions were fitted by the plots data respectively. The model of nonlinear regression of a unary cubic equation at $30 \mathrm{~m} \times 30 \mathrm{~m}$ resolution was: 


$$
y=-27.570 x^{3}+30.449 x^{2}+32.340 x-10.805
$$

The model of nonlinear regression of a unary cubic equation at $270 \mathrm{~m} \times 270 \mathrm{~m}$ resolution was:

$$
y=-51.628 x^{3}+86.704 x^{2}-24.764 x+8.928
$$

Finally, we use these regression models and the band4, band5 and band7 from Landsat TM remote sensing image to estimate the forest carbon density distribution and export the distribution maps on corresponding resolution.

\subsubsection{Sequential Gaussian co-simulation}

Based on the geostatistical variation function, plots data and remote sensing image of Landsat TM, sequential Gaussian co-simulation estimated the forest carbon density under the stochastic simulation method which could export the forest carbon density estimation in every pixel.

The method of sequential Gaussian co-simulation assumed that the estimated carbon density of each pixel was calculated from a random function of the random variable $Z(u)$. The implementation or estimate is obtained from random sampling from the conditional cumulative distribution function of the sample data and the existing estimates. And then assumed the distribution is normal and the remote sensing image data in estimated position was used to determine the conditional distribution ${ }^{[9]}$.

The following basic steps involved in the process of sequential Gaussian co-simulation (SGS) were made:

1) An estimated order of each pixel was set by random sampling method.

2) In each pixel position $u$, the mean and variance value of conditional cumulative distribution function were calculated with the method of simple co-Kriging.

3) The estimated value of pixel position $u$ was sampled from this conditional cumulative distribution function.

Repeat step 1) to 3, until all pixels had the estimated results of carbon density, and finally the forest carbon density distribution map of the whole study area was obtained. In order to improve the accuracy of the model, this process was repeated for $L$ times, and then obtained $L$ distribution maps. Finally, the mean, variance and probability of forest carbon density distribution were calculated. Study and analyze the mean map of forest carbon density distribution.

In this study, the cube root transformed effective carbon density which approximately met the normal distribution (including zero value data) was used in sequential Gaussian co-simulation. The important variation function was modeled in VARIONWIN (Pannatier, 1996). The standardized spherical model in scale of $30 \mathrm{~m} \times 30 \mathrm{~m}$ and $270 \mathrm{~m} \times 270 \mathrm{~m}$ is:

$$
\gamma_{s}(|h|)=0.63+0.37\left[1.5|h| / 8198.63-0.5(|h| / 8198.63)^{3}\right]
$$

Where $\gamma_{\mathrm{s}}(h)$ is the standard semi-variance; $h$ is the distance. 
Figure 3 showed the range in variation function was $8198.63 \mathrm{~m}$. Range is on behalf of the maximum distance of spatial autocorrelation among variables. Within this range, the observed values are spatial correlated and outside the range, the observed values are independent of each other. In the process of sequential Gaussian co-simulation, the search radius can be referred to the range value of the variation function model.

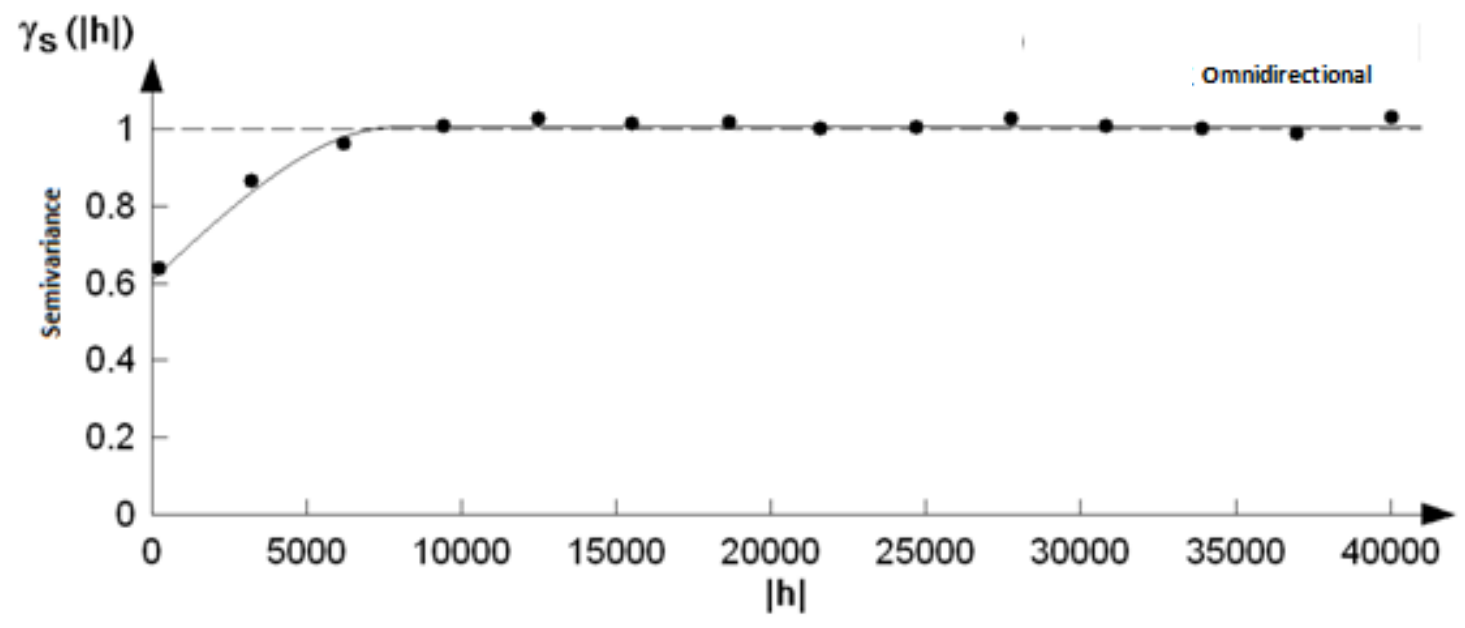

\author{
Separation distance/m; \\ -Experimental Value; -Simulated Value
}

Figure 3 Standard variogram

Based on the model of variation function and above-ground carbon density, with the method of sequential Gaussian co-simulation, we can estimate the whole county forest carbon density and its distribution at $30 \mathrm{~m} \times 30 \mathrm{~m}$ and $270 \mathrm{~m} \times 270 \mathrm{~m}$ resolution respectively.

\title{
3 Results and Analysis
}

3.1 Comparative analysis of estimated results with measured value estimation in the method of regression and sequential Gaussian co-simulation respectively in the same scale

In different scales, the above-ground forest carbon distribution maps based on the regression and sequential Gaussian co-simulation showed clearly that the carbon density around the study area was higher than that in middle area, which was accordant with the feature distribution of Xianju, as displayed in figure 4 and figure 5 . In figure 4 , the pixel size is $30 \mathrm{~m} \times 30 \mathrm{~m}$, the estimated above-ground forest carbon stock in the study area by means of regression is $5246749.81 \mathrm{Mg}$, the maximum carbon density is $68.8957 \mathrm{Mg} / \mathrm{hm}^{2}$, the smallest carbon density is $0.3917 \mathrm{Mg} / \mathrm{hm}^{2}$, the average carbon density is $14.6401 \mathrm{Mg} / \mathrm{hm}^{2}$ and the standard deviation is 7.6794 . However, the estimated total forest carbon stock by means of simulation is $5692875.69 \mathrm{Mg}$, the maximum carbon density is $73.9782 \mathrm{Mg} / \mathrm{hm}^{2}$, the smallest carbon density is $0.0344 \mathrm{Mg} / \mathrm{hm}^{2}$, the average 
carbon density is $15.8850 \mathrm{Mg} / \mathrm{hm}^{2}$ and the standard deviation is 8.8878 .

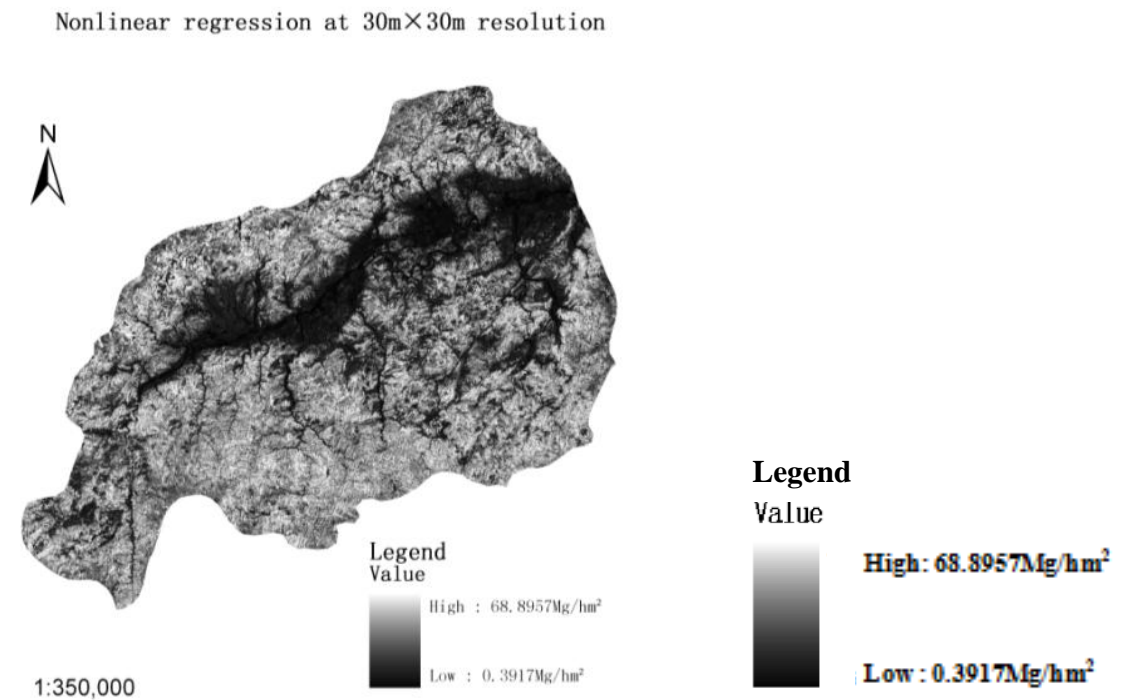

Sequential Gaussian co-simualtion at $30 \mathrm{~m} \times 30 \mathrm{~m}$ resolution

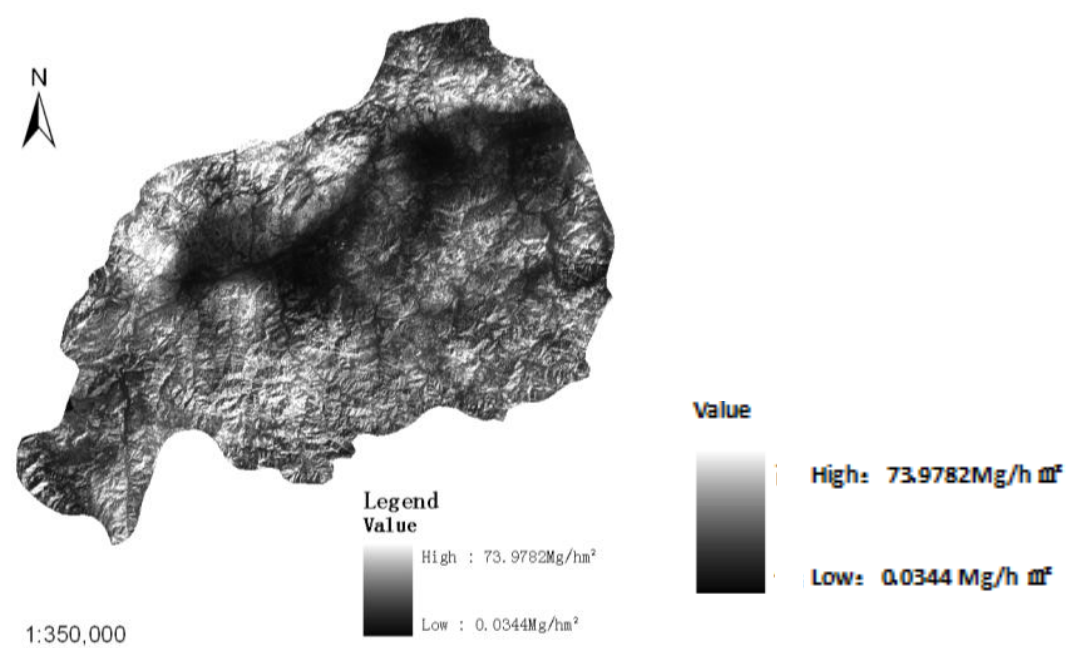

Figure 4 Estimated map of carbon density (above-ground) for the study area on $30 \mathrm{~m} \times 30 \mathrm{~m}$ resolution

In figure 5 , the pixel size is $270 \mathrm{~m} \times 270 \mathrm{~m}$, with the method of regression, the estimated forest carbon stock is $5194247 \mathrm{Mg}$, the maximum carbon density is $45.9351 \mathrm{Mg} / \mathrm{hm}^{2}$, the smallest carbon density is $0.6331 \mathrm{Mg} / \mathrm{hm}^{2}$, the average carbon density is $14.4936 \mathrm{Mg} / \mathrm{hm}^{2}$, and the standard deviation is 5.8915 . In the same resolution, the simulated forest carbon stock is $5030871.79 \mathrm{Mg}$, the maximum carbon density is $54.0033 \mathrm{Mg} / \mathrm{hm}^{2}$, the smallest carbon density is $0.4284 \mathrm{Mg} / \mathrm{hm}^{2}$, the average carbon density is $14.0378 \mathrm{Mg} / \mathrm{hm}^{2}$, and the standard deviation is 7.5184 .

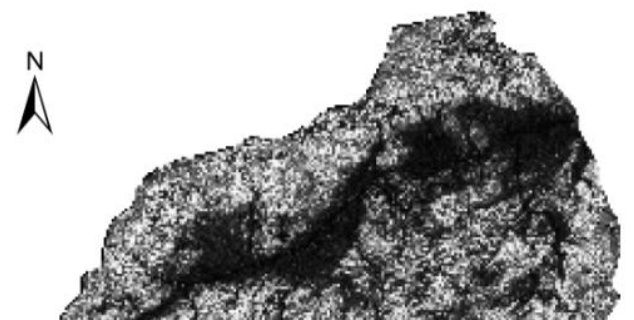




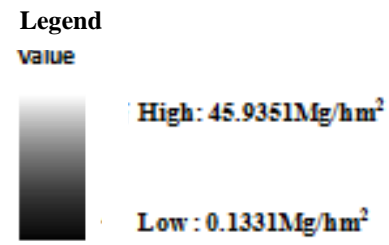

Sequential Gaussian co-simualtion at $270 \mathrm{~m} \times 270 \mathrm{~m}$ resolution
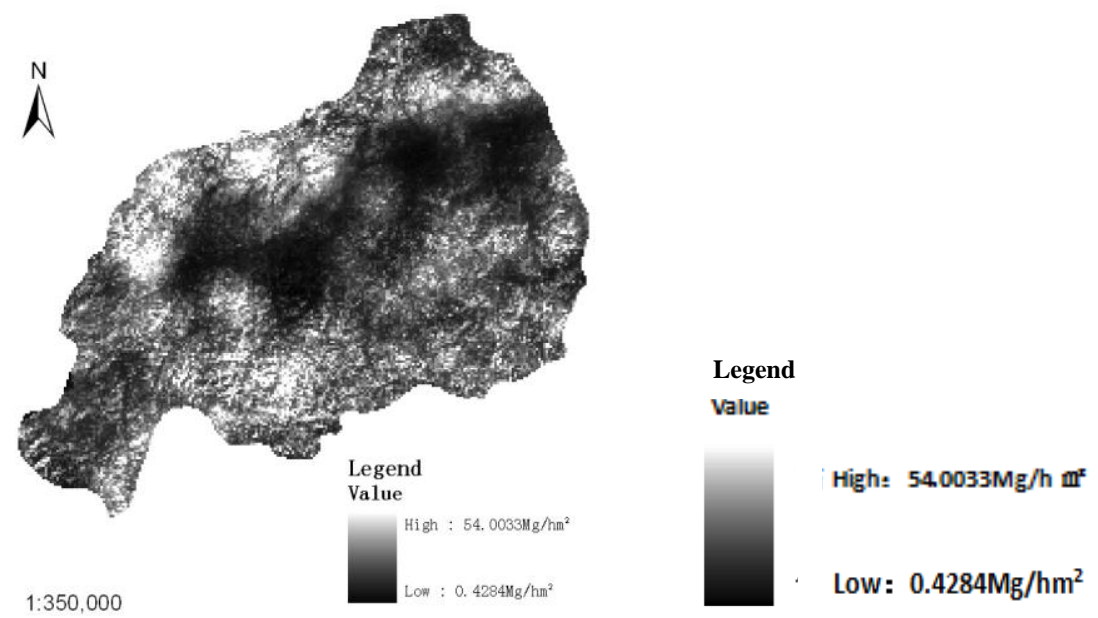

Figure 5 Estimated map of carbon density (above-ground) for the study area on $270 \mathrm{~m} \times 270 \mathrm{~m}$ resolution

According to the forest inventory (plot) data in Xianju county, Zhejiang, from 2008, estimated by the method of random sampling, the regional carbon storage is $5289437.11 \mathrm{Mg}$, the average carbon density value of the sample is $14.7593 \mathrm{Mg} / \mathrm{hm}^{2}$, the maximum value is 86.913 $8 \mathrm{Mg} / \mathrm{hm}^{2}$ and the minimum value is $0.0000 \mathrm{Mg} / \mathrm{hm}^{2}$. From the overall results, the existing samples can estimate forest carbon stock directly and the standard deviation of the estimated value can be gotten easily, however, the spatial distribution of carbon storage is unable to obtain due to random sampling can only estimate the total amount of carbon value, while the regression and sequential Gaussian co-simulation can estimate the distribution of forest carbon. The results estimated by sequential Gaussian co-simulation which consider the spatial distribution of carbon storage are better.

The estimated results of the regression and sequential Gaussian co-simulation are statistically compared with the results of random sampling method, the contrastive analysis results at $30 \mathrm{~m} \times 30 \mathrm{~m}$ resolution are shown in table1.

Table 1 Contrastive analysis between the two estimates and plot data at $30 \mathrm{~m} \times 30 \mathrm{~m}$ resolution 


\begin{tabular}{cccccc}
\hline Item & Simulation & Regression & Estimation & $\begin{array}{c}\text { Difference between } \\
\text { simulation and estimation }\end{array}$ & $\begin{array}{c}\text { Difference between } \\
\text { regression and estimation }\end{array}$ \\
\hline Total carbon/Mg & 5692875.69 & 5246749.81 & 5289437.11 & 403438.58 & -42687.30 \\
Mean $/\left(\mathrm{Mg} / \mathrm{hm}^{2}\right)$ & 15.8850 & 14.6401 & 14.7593 & 1.1257 & -0.1192 \\
Maximum $/\left(\mathrm{Mg} / \mathrm{hm}^{2}\right)$ & 73.9782 & 68.8957 & 86.9138 & -12.9356 & -18.0181 \\
Minimum $/\left(\mathrm{Mg} / \mathrm{hm}^{2}\right)$ & 0.0344 & 0.3917 & 0.0000 & 0.0344 & 0.3917 \\
Standard deviation & 8.8878 & 7.6749 & 15.2728 & -6.3850 & -7.5979 \\
\hline
\end{tabular}

From table 1, based on $30 \mathrm{~m} \times 30 \mathrm{~m}$ resolution, the total carbon estimated by simulation is more than the results of random sampling method, whereas the total carbon estimated by regression estimation is less. Based on measured plots data, the total carbon estimated by sequential Gaussian co-simulation is $7.63 \%$ more, while the results estimated by regression is $0.81 \%$ less. Compared with the simulated results, the total carbon estimated by regression is $446125.88 \mathrm{Mg}$ less, and the mean carbon density is $1.2449 \mathrm{Mg} / \mathrm{hm}^{2}$ less, the maximum carbon density is $5.0825 \mathrm{Mg} / \mathrm{hm}^{2}$ less, whereas the minimum carbon density is $0.3573 \mathrm{Mg} / \mathrm{hm}^{2}$ more.

From this, the range of regional forest carbon density distribution has varying degrees of narrowing by these two methods, whereas the range of carbon density estimated by sequential Gaussian co-simulation changes small, the total increases that the result is closer to the actual. And the carbon density distribution range estimated by regression is narrowed, the mean shift, the upper limit obviously moves down, the carbon density distribution is relatively flat on the whole. The reason why the estimated range of carbon density by nonlinear regression of a unary cubic equation is narrowed is that there are many non-forest plots which affect the accuracy. The standard deviation from two estimated methods differ greatly from the standard deviation 15.2728 estimated by random sampling. The main reason is that the number of plots used to calculate standard deviation is much different, and the number of plots used to estimate with the method of random sampling is significantly less than the number of pixels.

The remote sensing image of $270 \mathrm{~m} \times 270 \mathrm{~m}$ resolution is sampled from $30 \mathrm{~m} \times 30 \mathrm{~m}$ pixel gray value by the method of nearest neighbor interpolation. At the $270 \mathrm{~m} \times 270 \mathrm{~m}$ resolution, the forest carbon density and its distribution is estimated by nonlinear regression of a unary cubic equation and sequential Gaussian co-simulation respectively, the results are shown in table 2. Compared with the random sampling estimation results, the total carbon estimated by sequential Gaussian co-simulation is $258565.32 \mathrm{Mg}$ less. After up-scale, the new blocks within the pixel value are influenced by the "smoothing" effect, which makes the range of carbon density narrowed obviously, and the value of total carbon is less. Each pixel becomes easy to contain more different types of features that leads to the result of estimation is weaker than the reflection of ground object classification, which diminishes the estimated ability to distinguish object types. Thus, the 
estimated results on the large scale are not as close to the measured values as the estimated results on the small scale. However, the results estimated by sequential Gaussian co-simulation are still better than the results estimated by nonlinear regression of a unary cubic equation.

\begin{tabular}{cccccc}
\multicolumn{5}{c}{ Table 2 Contrastive analysis between the two estimates and plot data at $270 \mathrm{~m} \times 270 \mathrm{~m}$ resolution } \\
\hline Item & Simulation & Regression & Estimation & $\begin{array}{c}\text { Difference between } \\
\text { simulation and estimation }\end{array}$ & $\begin{array}{c}\text { Difference between } \\
\text { regression and estimation }\end{array}$ \\
\hline Total carbon/Mg & 5030871.79 & 4784243.10 & 5289437.11 & -258565.32 & -505194.1124 \\
Mean $/\left(\mathrm{Mg} / \mathrm{hm}^{2}\right)$ & 14.0378 & 13.3496 & 14.7593 & -0.7215 & -1.4097 \\
Maximum $/\left(\mathrm{Mg} / \mathrm{hm}^{2}\right)$ & 54.0033 & 45.9351 & 86.9138 & -32.9105 & -40.9787 \\
Minimum $/\left(\mathrm{Mg} / \mathrm{hm}^{2}\right)$ & 0.4284 & 0.6331 & 0.0000 & 0.4284 & 0.6331 \\
Standard deviation & 7.5184 & 5.8915 & 15.2728 & -7.7544 & -9.3813 \\
\hline
\end{tabular}

3.2 Comparative analysis of estimated results with measured value estimation in the method of regression and sequential Gaussian co-simulation respectively in the different scales

According to table 1 and table 2, compared with the estimated results by means of sequential Gaussian co-simulation at $30 \mathrm{~m} \times 30 \mathrm{~m}$ resolution, the estimated total carbon at $270 \mathrm{~m} \times 270 \mathrm{~m}$ resolution is $11.63 \%$ less, the mean carbon density is $1.8472 \mathrm{Mg} / \mathrm{hm}^{2}$ less, the maximum carbon density is $19.9749 \mathrm{Mg} / \mathrm{hm}^{2}$ less, and the minimum carbon density is $0.3940 \mathrm{Mg} / \mathrm{hm}^{2}$ more. After up-scale, the distribution range of carbon density estimated by sequential Gaussian co-simulation is narrowed obviously with its upper limit moving down and its lower limit moving up, which reduces the estimated total carbon in a certain extent.

Compared with the estimated results by means of nonlinear regression of a unary cubic equation at $30 \mathrm{~m} \times 30 \mathrm{~m}$ resolution, the estimated total carbon at $270 \mathrm{~m} \times 270 \mathrm{~m}$ resolution is $8.82 \%$ less, and the range of carbon density distribution is narrowed obviously because the estimated maximum carbon density is $22.9606 \mathrm{Mg} / \mathrm{hm}^{2}$ less. This situation may be related with the distribution status of the original data. Xianju county is surrounded by high carbon density forest land and the intermediate region is filled with the majority of low carbon density of non-forest land, so that the degree of change in the range of carbon density distribution at the $30 \mathrm{~m} \times 30 \mathrm{~m}$ resolution is much more prominent than the $270 \mathrm{~m} \times 270 \mathrm{~m}$ resolution and is more sensitive for the spatially continuous variation. After up-scale, the new pixel values are influenced by the "smooth" effect, which makes the spatial distribution of carbon density relatively flat, which means the continuously change ability of forest biomass spatial distribution to distinguish the no-woodland and non-forest land is decreased. Overall, at the same scale, the results estimated by sequential Gaussian co-simulation which are closer to the measured values are better than that estimated by regression. At the small scale, the results estimated by sequential Gaussian co-simulation are better able to reflect the spatial continuous changes of carbon density distribution. However, there are 
more deviation between measured values and estimated results at large scale.

In order to comprehensively analyze the characteristics of the two estimation methods, the difference operation of each pixel value estimated by sequential Gaussian co-simulation and nonlinear regression of a unary cubic equation is carried out, the results are shown in figure 6 and figure 7. The range of difference is $-64.1334 \sim 56.1176 \mathrm{Mg} / \mathrm{hm}^{2}$ at small scale, whereas the range of difference is $-52.6620 \sim 39.3099 \mathrm{Mg} / \mathrm{hm}^{2}$ at large scale. Taking the value 0 as center, the difference values at two scales in the positive and negative directions are not small. In the carbon density distribution, the ranges of two methods are different. The range of carbon density estimated by sequential Gaussian co-simulation is wider and better to distinguish no-woodland and non-forest areas. After up-scale, the range of carbon density estimated by sequential Gaussian co-simulation is narrowed obviously, which makes estimated results relatively flat and the ability to reflect the continuous change of forest carbon distribution is weakened.

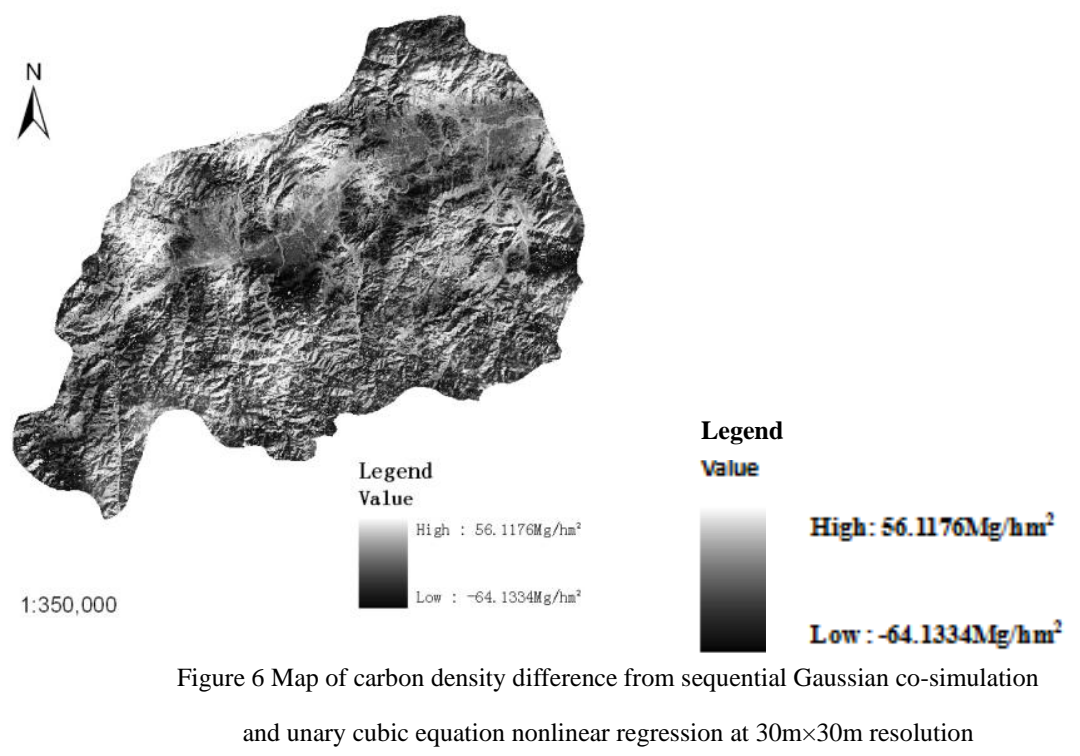




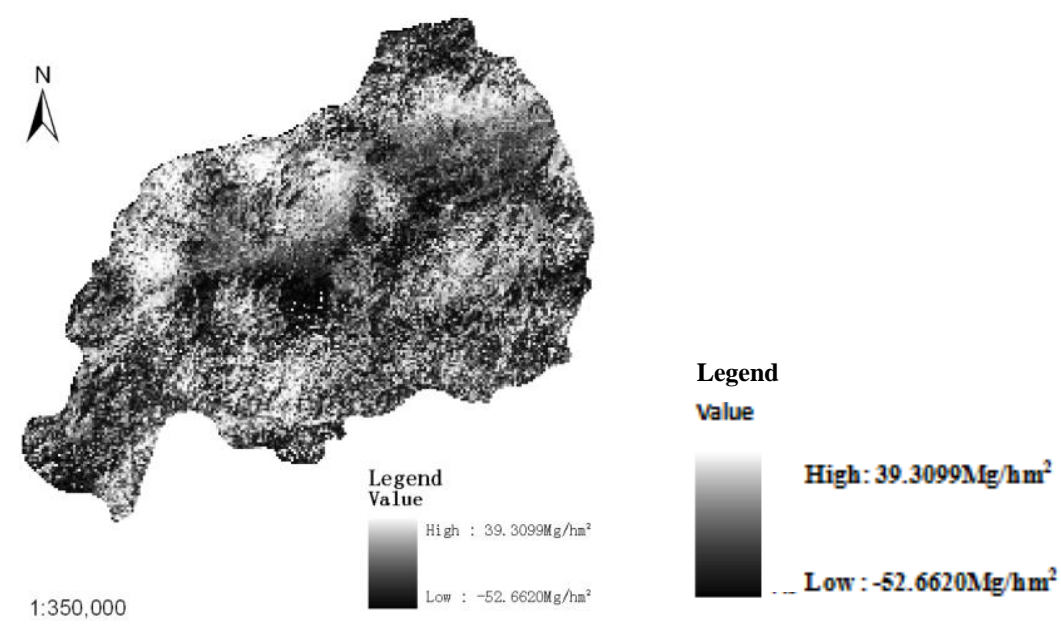

F1gure / Miap of carbon density difterence trom sequential Gaussian co-simulation

and unary cubic equation nonlinear regression at $270 \mathrm{~m} \times 270 \mathrm{~m}$ resolution

A statistical analysis of the carbon density difference at the same scale is carried out. The results are shown in table 3 and table 4 . In the table 3 , from the difference results at $30 \mathrm{~m} \times 30 \mathrm{~m}$ resolution, the mean carbon density difference calculated by two methods is $4.8105 \mathrm{Mg} / \mathrm{hm}^{2}$, which is $30.28 \%$ of the mean carbon density estimated by sequential Gaussian co-simulation and $32.86 \%$ of regression. The maximum carbon density difference is $56.1176 \mathrm{Mg} / \mathrm{hm}^{2}$ and the minimum carbon density difference is $-64.1334 \mathrm{Mg} / \mathrm{hm}^{2}$. Comparing with the figure 4 , the results estimated by sequential Gaussian co-simulation at same scale, the larger the difference, the higher the regional pixel values are. In these large difference areas, there are high carbon density areas, which mean the regression underestimating this forest carbon density. In small difference areas, there are non-forest areas generally, which mean the regression overestimating this forest carbon density. The results of statistical analysis show that the minimum carbon density difference is 1864.34 times than the minimum carbon density estimated by sequential Gaussian co-simulation and 163.73 times than that estimated by regression. The results mean that the minimum carbon density estimated by regression is obviously higher than that estimated by sequential Gaussian co-simulation. Compared with the carbon density difference results at $30 \mathrm{~m} \times 30 \mathrm{~m}$ resolution, the minimum difference between simulation and regression improve the relative ratio obviously at $270 \mathrm{~m} \times 270 \mathrm{~m}$ resolution. It means that after up-scale, the estimation ability of the minimum carbon density by the method of sequential Gaussian co-simulation is weakened, that is, the ability to distinguish non-forest land is worse than that at small scale.

Table 3 Analysis on the map of carbon density difference at $30 \mathrm{~m} \times 30 \mathrm{~m}$ resolution

\begin{tabular}{cccc}
\hline Item & The difference & Difference divided by simulation result & Difference divided by regression result \\
\hline Total $/ \mathrm{Mg}$ & 1723993.8783 & 0.3028 & 0.3286 \\
Mean $/\left(\mathrm{Mg} / \mathrm{hm}^{2}\right)$ & 4.8105 & 0.3028 & 0.3286 \\
Maximum $/\left(\mathrm{Mg} / \mathrm{hm}^{2}\right)$ & 56.1176 & 0.7586 & 0.8145 \\
Minimum $/\left(\mathrm{Mg} / \mathrm{hm}^{2}\right)$ & -64.1334 & -1864.3430 & -163.7309 \\
Standard deviation & 7.6435 & - & - \\
\hline
\end{tabular}

Table 4 Analysis on the map of carbon density difference at $270 \mathrm{~m} \times 270 \mathrm{~m}$ resolution 


\begin{tabular}{|c|c|c|c|}
\hline Total/Mg & 1806513.8636 & 0.3591 & 0.3776 \\
\hline Mean $/\left(\mathrm{Mg} / \mathrm{hm}^{2}\right)$ & 5.0408 & 0.3591 & 0.3776 \\
\hline Maximum/(Mg/hm²) & 39.3099 & 0.7279 & 0.8558 \\
\hline Minimum/(Mg/hm²) & -52.6620 & -122.9272 & -83.1812 \\
\hline Standard deviation & 5.7257 & - & - \\
\hline
\end{tabular}

3.3 Comparative analysis of estimated plot results with measured value in the method of regression and sequential Gaussian co-simulation respectively in the different scales

In order to judge these two methods more accurately in different scales, now we compare forest carbon density estimation from estimated results with the plot measurement. The carbon densities of the plots simulation and regression estimation are compared with the measured plot carbon density by overlaying the images. The results are shown in figure 8 and figure 9 based on $30 \mathrm{~m} \times 30 \mathrm{~m}$ and $270 \mathrm{~m} \times 270 \mathrm{~m}$ resolutions.

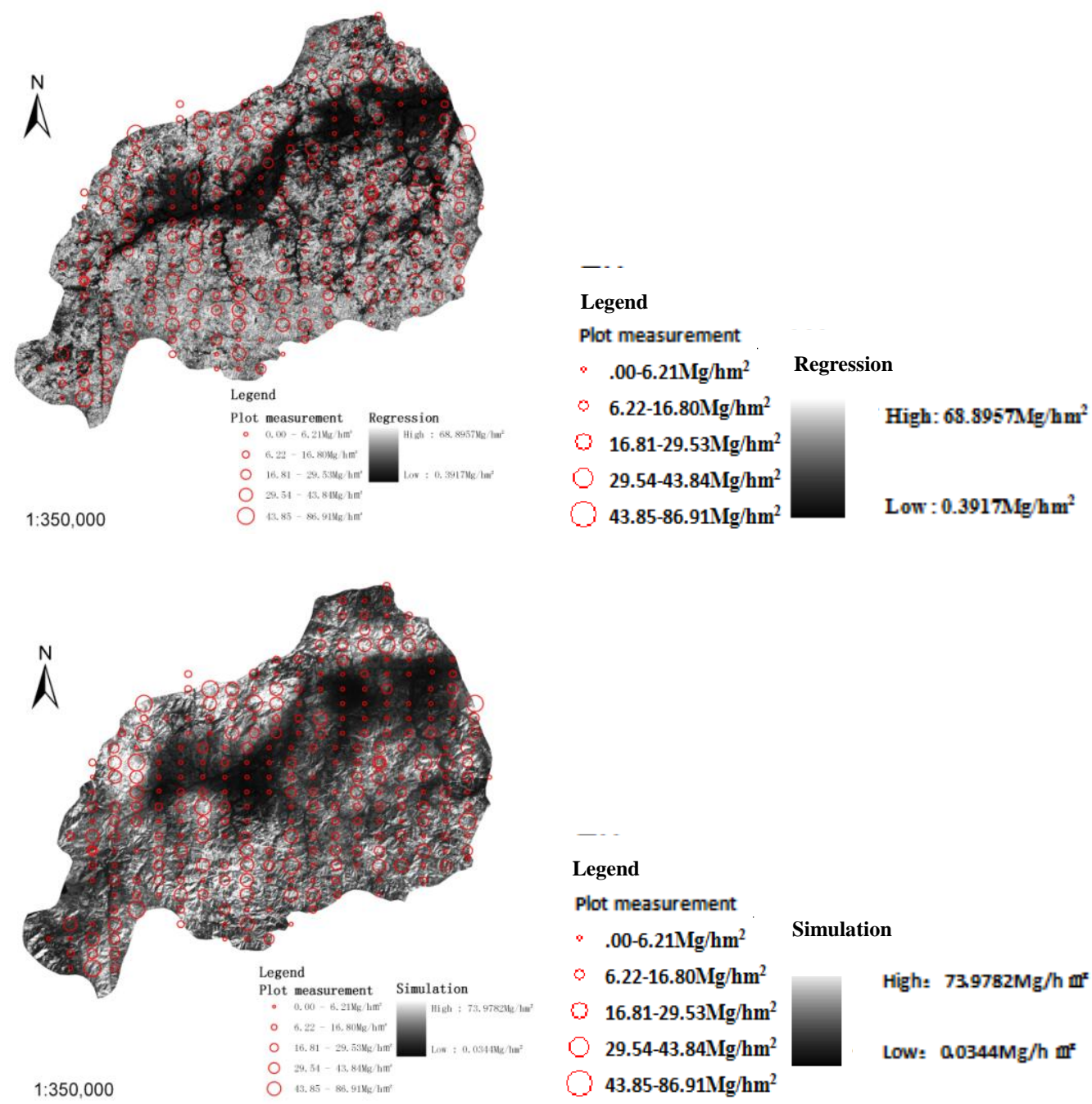

Figure 8 Forest carbon densities from sequential Gauss co-Simulation and unary cubic equation nonlinear regression 

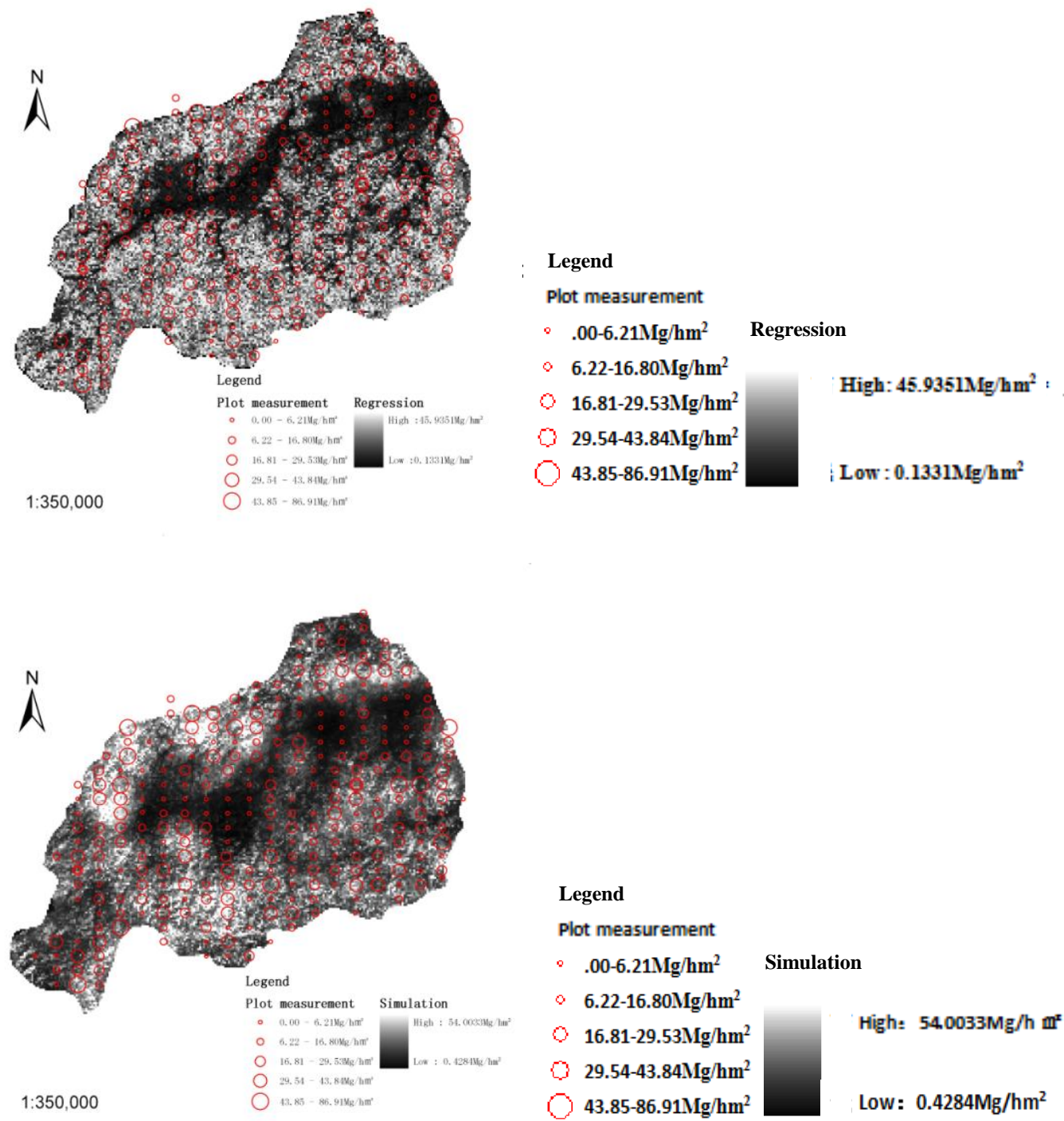

Figure 9 Forest carbon densities from sequential Gaussian co-simulation and unary cubic equation nonlinear regression

compared with the plot measurement at $270 \mathrm{~m} \times 270 \mathrm{~m}$ resolution

These figures show that sequential Gaussian co-simulation and regression estimation have good consistency with the plots measurement. As illustrated in the legend, the larger the hollow circle represents the larger measured values of plots carbon density. At the same time the higher of the pixel values corresponding to the images legends also shows the range of the carbon density estimation results at $30 \mathrm{~m} \times 30 \mathrm{~m}$ resolution. The carbon density distribution in sequential Gaussian co-simulation is $0.0334 \mathrm{Mg} / \mathrm{hm}^{2} \sim 73.9782 \mathrm{Mg} / \mathrm{hm}^{2}$ and the range estimated by regression is 0.391 $7 \mathrm{Mg} / \mathrm{hm}^{2} \sim 68.8957 \mathrm{Mg} / \mathrm{hm}^{2}$. The range of carbon density estimated by sequential Gaussian co-simulation is wider than that estimated by regression. The minimum carbon density simulated results are closer to 0 , which can be better to reflect the distribution of non-forest land. In general, the regional forest carbon densities, estimated by sequential Gaussian co-simulation and regression have the same change. Around the area, there is high carbon density forest land and in 
the intermediate region, there is filled with the low carbon density of non-forest land. After up-scale, the ability to reflect the continuous change of estimated carbon density distribution declined as well as the degree of distinction, but the simulated results are still closer to the real situation than regression estimation.

Extracting the plots estimated values, statistically analyze those with the plots measured carbon density, and further analyze the features of carbon density in different scales. In order to get a better analysis for each model, using three accuracy measures: $\mathrm{R}^{2}$ (determination coefficient), SEE (the standard error of estimate) and MPSE (the average percentage error). Its computation formula is as follows ${ }^{[21-24]}$ :

$$
\begin{aligned}
& R^{2}=1-(n-1) /(n-p) \sum\left(y_{i}-\hat{y}_{i}\right)^{2} / \sum\left(y_{i}-y\right)^{2} \\
& S_{E, E}=\sqrt{\sum\left(y_{i}-\hat{y}_{i}\right)^{2} /(n-p)} \\
& M_{P, S, E}=\frac{1}{n} \sum_{i=1}^{n}\left|\left(y_{i}-\hat{y}\right) / \hat{y}_{i}\right| \times 100
\end{aligned}
$$

Where $n$ is the number of plots; $p$ is the number of parameter; $y_{i}$ and $\hat{y}_{i}$ are the measured values and estimated values of buck biomass; $y$ is the average measured values of buck biomass. The result is in table 6:

Table 6 A testing of model accuracy at different scales

\begin{tabular}{cccccc}
\hline Model & Scale & $\begin{array}{c}\text { Standard } \\
\text { deviation }\end{array}$ & $\mathrm{R}^{2}$ & SEE & MPSE \\
\hline Sequential Gauss co-Simulation & $30 \mathrm{~m} \times 30 \mathrm{~m}$ & 11.8707 & 0.6203 & 11.9990 & 65.5526 \\
& $270 \mathrm{~m} \times 270 \mathrm{~m}$ & 13.7010 & 0.2383 & 13.7257 & 13.4250 \\
Unary Cubic Equation & $30 \mathrm{~m} \times 30 \mathrm{~m}$ & 7.6749 & 0.1353 & 120.1224 \\
nonlinear regression & $270 \mathrm{~m} \times 270 \mathrm{~m}$ & 5.8915 & 0.0703 & 15.8410 & 134.8824 \\
\hline
\end{tabular}

In theory, the more the value of $\mathrm{R}^{2}$ is close to 1 , the smaller the value of standard errors and relative errors are, the higher precision the mode is. In this way, showed in table 6, where the scale is $30 \mathrm{~m} \times 30 \mathrm{~m}$, in the simulated results, the $\mathrm{R}^{2}$ is 0.6203 , which is higher than regression results. And the values of SEE and MPSE are lower than regression estimation, which mean the results estimated by sequential Gaussian co-simulation are more accurate than regression. With the scale level enlarged, both of $\mathrm{R}^{2}$ are down, fitting precision between estimated results and measured plots values get lower. The values of SEE and MPSE are higher, which means the error of estimated results and plots measured values is higher at large scale. The smooth effect in the increase of pixel size is one of the most serious reasons. In addition to that, with a supervised classification in original TM image, the average patch size of the forest with whole image is $57018.9 \mathrm{~m}^{2}$ (about $238.8 \mathrm{~m} \times 238.8 \mathrm{~m}$ ) which is smaller than $270 \mathrm{~m} \times 270 \mathrm{~m}$. The bigger degree of the ground broken will lead to the increase of the error. And there are many non-forest plots, which influence the accuracy and correlation of results on a certain extent. According to the standard deviation, the result of sequential Gaussian co-simulation in $30 \mathrm{~m} \times 30 \mathrm{~m}$ resolution is 11.8707 , compared with the 
original data of standard deviation (15.2738) only lows 3.4031, which is closer to the original data of standard deviation than regression estimation. It means sequential Gaussian co-simulation can better reflect the uncertainty of carbon density distribution in the study area. Although the estimated results at $270 \mathrm{~m} \times 270 \mathrm{~m}$ resolution showed the standard deviation of sequential Gaussian co-simulation becomes lower, it is still better than regression estimation. The distribution of carbon density is more stable after up-scale and the deviation with continuous changes of actual carbon distribution is larger. Overall, sequential Gaussian co-simulation can better maintain the overall intensity of spatial variation in small scale on the basis of ensuring estimation precision.

\section{Conclusion and discussion}

Regression and simulation both can be used to estimate the carbon density and forest spatial distribution in the study area. Based on Forest Inventory (plot) data and the remote sensing image data, by means of these two methods, we can accurately estimate a large regional forest carbon density and its distribution. Compared with the results of regression, the total carbon estimated by simulation is closer to the reality, the range of distribution is wider, and the model's precision is higher. The estimated results can better reflect the spatial distribution of carbon density and contribute to the sustainable development of regional forest management and regional economic and social sustainable development. Because of many non-forest plots, the forest carbon density distribution estimated by nonlinear regression of a unary cubic equation is relatively narrowed, and the ability to distinguish the non-woodland and non-forest land is decreased.

Resampling the image from $30 \mathrm{~m} \times 30 \mathrm{~m}$ resolution to $270 \mathrm{~m} \times 270 \mathrm{~m}$ resolution, the upper limit is down, the range of carbon density is narrowed, the total carbon density is decreased and the fitting degree between the estimation from corresponding plots and the measured value is lower. The image which is resampled by the means of adjacent re-sampling into large scale that smoothes the pixel values on a certain extent reduces the ability to represent the continuous change of carbon distribution. Moreover, after up-scale, the ground breaking degree increases and the patch size is less than pixel size, the error will increase. However, the results estimated by sequential Gaussian co-simulation can better reflect the distribution of carbon density than regression. In general, the estimation of carbon density distribution and uncertainty from a small scale by means of sequential Gaussian co-simulation has an obvious advantage.

A comparative analysis of the results at small scale and large scale carbon density estimation can be achieved by the means of sequential Gaussian co-simulation and nonlinear regression of a unary cubic equation. But in this study, we just use adjacent re-sampling method to greaten scale, the calculation of the mean and variance of the pixel will deviate from the actual situation which affects the accuracy of estimated results. 
To obtain precise results by the means of sequential Gaussian co-simulation requires the above-ground plots to match the position pixels of remote sensing image accurately and the brightness of selected feature should have a certain relationship with the target characteristic ${ }^{[9]}$. There is a certain matching error between plot position and pixel of Landsat TM, which causes the matching deviation between estimated value and true value.

\section{References:}

[1] Shi J, Liu J Y, Gao Z Q, Cui L L. Research Advances of the Influence of Afforestation on Terrestrial Carbon Sink. Progress In Geography, 2004, 23(2): 58.67.

[2] Wang X K, Feng Z W, Ou Y Z Y. Vegetation carbon storage and density of forest ecosystems in China. Chinese Journal of Applied Ecology, 2001, 12(1): 13.16.

[3] Bartel P. Soil carbon sequestration and its role in economic development: A donor perspective. Journal of Arid Environments, 2004, 59(3): 643.644.

[4] Fang J Y, Chen A P, Peng C H, Zhao S P, Ci L J. Changes in forest biomass carbon storage in China between 1949 and 1998. Science, 2001, 292(5525): 2320.2322

[5] Pan Y D, Luo T X, Birdsey R, Hom J, Melillo J. New estimates of carbon storage and sequestration in China's forests: Effects of age-class and method on inventory-based carbon estimation. Climate Change, 2004, 67(2-3): 211.236.

[6] Li K R, Wang S Q, Cao M K. Vegetation and soil carbon storage in China. Science in China(Series D), 2003, 33(1): 72.80 .

[7] Zhou Y R, Yu Z L, Zhao S D. Carbon storage and budget of major Chinese forest types. Acta Phyyoecologics Sinica, 2000, 24(5): 518.522.

[8] Wu Z M, Li Y D, Zeng Q B, Zhou G Y, Chen B F, Du Z H, Lin M X. Carbon pool of tropical mountain rain forests in Jianfengling and effort of clear-cutting on it. Chinese Journal of Applied Ecology, 1998, 9(4): 341.344

[9] Zhang M Z, Wang G X, Zhou G M, Ge H L, Xu L H, Zhou Y Z. 2009. Mapping of forest carbon by combining forest inventory data and satellite images with co-simulation based up-scaling method. Acta Ecologica Sinica, 29(6): 2919.2928

[10] Wang R D, Hu G D. Linear Geostatistics. Beijing: Geological Publishing House, 1988: 123.163

[11] Goovaerts P. Geostatistics for Natural at Resources Evaluation. New York: Oxford University Press, 1997.

[12] Castrignanò A, Buttafuoco G. Geostatistical stochastic simulation of soil water content in a forested area of south Italy. Biosystems Engineering, 2004, 87(2): 257.266.

[13] Zhao Y C, Huang B, Sun W X, Shao X X, Wang Z G.. Uncertainty assessment of the spatial patterns of copper contents in topsoil in Zhejiang city, China. Acta Pedologica Sinica, 2007, 44(6): 974.981.

[14] Delbari M, Afrasiab P, Loiskandl W. Using sequential Gaussian simulation to assess the field-scale spatial uncertainty of soil water content. Catena, 2009, 79(2): 163.169.

[15] Cliftom P M, Neuman S P. Effects of Kriging and inverse modeling on conditional simulation of the Avra Valley aquifer in southern Arizona. Water Resources Research, 1982, 18(4): 1215.1234.

[16] Zhu H, Journel A G. Indicator conditioned estimator. Transactions of the Society Mining Engineers, 1989, 286: 1880.1886

[17] Shi Z, Li Y, Cheng J L. 2007. Stochastic simulation of spatial distribution and uncertainty assessment of heavy in paddy soil. Environmental Science, 28(1): 209.214.

[18] Chai X R, Huang Y F, Fan X Y. Enhancing spatial prediction of soil properties using elevation. Scientia Agricultura Sinica, 2007, 40(12): 2766.2773. 
[19] Shen X, Zhang M Z, Qi X B. 2011. Comparison of regional forest carbon estimation methods based on regression and stochastic simulation. Scientia Silvae Sinicae, 47(6): 1.8.

[20] Jin Y F, Zhang M Z, Guo H R, He W A. 2013. Comparison of forest carbon spatial distribution based on Kriging interpolation and sequential Gaussian co-simulation. Journal of Southwest Forestry University, 33(6): 32.37 .

[21] Parresol B R. Assessing tree and stand biomass: a review with examples and critical comparisons. Forest Science, 1999, 45(4): 573.593.

[22] Parresl B R. Additivity of nonlinear biomass equations. Canadian Journal of Forest Research, 2001, 31(5): 865.878 .

[23] Zeng W S, Xiao Q H, Hu J, Liao Z Y et al. 2010. Establishment of single-tree biomass equations for Pinus massoniana in southern China. Journal of Central South University of Forestry \& Technology, 30(5): 50.55.

[24] Zabek L M, Prescott C E. Biomass equations and carbon content of aboveground leafless biomass of hybrid poplar in Coastal British Columbia. Forest Ecology and Management, 2006, 223(1-3): 291.302. 